Aus dem Neurologischen Institut des Herrn Privatdocenten Dr. L. Jacobsohn zu Berlin.

\title{
Ein Fall von Distomumerkrankung des Gehirns mit dem Symptomencomplex von Jackson'scher Epilepsie, von Chorea und Athetose.
}

\author{
Von \\ Dr. Taniguehi \\ aus Japan. \\ (Hierzu Tafel IV und V.)
}

Distomum pulmonale (Baelz), Distomum Ringeri (Cobbold) und Distomum Westermanni (Kerbert) kommt sehr häufig in Japan vor. Der Parasit ist hauptsächlich in den menschlichen Lungen sesshaft, in welchen er kleine cystenartige Höhlen bildet und sich klinisch als eine eigenartige parasitäre Haemoptoe kennzeichnet. Er kann aber auch oft in verschiedenen anderen Organen auftreten. Ich habe im Jahre 1892 über 2 Fälle berichtet. Im ersten Falle trat der Parasit in der Augenhöhle auf und im zweiten im Hodensack. Er kam in diesen Fällen als rundliche, multiloculäre, durch kleine Durchlöcherungen mit einander communicirende Cysten vor, welche in ihrem Innern eine gelblich weisse, dicke Flüssigkeit bargen. Ausserdem fanden sich in den Cysten eine ausserordentlich grosse Anzahl von Eiern, zwei lebendige und mehrere mumificirte Würmchen vor. Der Cystensack war äusserst elastisch, fast so stark wie die Gefässwand, nach aussen stark mit dem Nachbargewebe verwachsen und in der inneren Fläche fein gefaltet, aber die Falten selbst waren ziemlich glatt. Später haben Dr. Ubiyake und Dr. Wakabayashi ähnliche Beobachtungen über die Distomumcysten in den Augenlidern und in der Augenhöhle veröffentlicht. Noch interessanter ist die Cystenbildung im Gehirn. Dr. Otani hat zuerst einen Fall mitgetheilt, in welchem ein 26jähriger Mann, welcher 
schon lange an Lungendistomum litt, sonst aber gesund war, plötzlich allgemeine Epilepsie bekam und nach Verlauf von anderthalb Jahren starb. Bei der Section wurde ein hühnereigrosser Tumor und mehrere kleinere im rechten Stirn- und Hinterhauptslappen gefunden, welche aus mehrfächrigen, mit einander communicirenden, reiskorn- bis taubeneigrossen Cysten bestanden, und in einer von solchen wurden zwei Distomumwürmer angetroffen. Die Cysten enthielten eine gelblich dunkelbräunliche, dickfü̈ssige Inhaltsmasse und waren von einer starkgewucherten bindegewebigen Wand umschlossen. Der Cysteninhalt zeigte mikroskopisch viele Eier, Charcot-Leyden'sche und Haematoidin-Krystalle. Später berichtete er noch drei Fälle, aber nur über klinische Beobachtungen. Ferner sind noch Dr. Inouye, Yamagiwa und Katzurada zu erwähnen, welche interessante Mittheilungen über die durch Distomumeier verursachten Veränderungen des Gehirns veroffentlichten.

Inouye hat iiber 11 Fälle von Lungendistomumerkrankung mit Gehirnsymptomen berichtet, unter denen 6 Fülle halbseitige Krämpfe nit oder ohne gleichnamige oder gegenseitige Hemiparese, 2 Fälle allgemeine Epilepsie, 2 Fälle Hemiplegie und 1 Fall Seelenblindheit zeigten. Von diesen 11 Fällen gelangten 4 zur Section. Bei 2 von diesen 4 Fällen wurden keine anatomischen Veränderungen constatirt, und bei den anderen berichten Yamagiwa und Katzurada die genaueren Sectionsbefunde. Der von Yamagiwa publicirte Fall zeigte folgende Erscheimungen.

Ein 29jähriger Kuchenhändler, der bis zu șeinem 27. Lebensjahre gesund war; fiel plötzlich unter beftigem Schwindel und starken Convulsionen des linken Armes bewusstlos hin. Nach Verlauf von 2 Stunden etwa erholte er sich, und es blieb bei ihm starker Kopfschmerz und Schwindel zurück. Seitdem traten solche Anfälle täglioh 2-3 mal ein. Nach einem solchen Anfalle blieb bei ihm eine Parästhesie des linken Armes zurück, ans welcher sich allmählich eine Contractur desselben entwickelte. Ausserdem kamen im Verlauf der Krankheit noch linksseitige Facialislälımung, Sprachstörung, Gedächtnissschwäche und undeutliches Sehen am linken Auge binzu. Nach 2Jahren starb der Patient an allgemeiner Erschöpfung.

Der Sectionsbefund war folgender: Die rechte Grosshirnhemisphäre ist in ihrer seitlichen hinteren Region mit der Himhaut verwachsen; hier ist auch die Rindensubstanz von harter Consistenz. In dieser sieht man dunkelgrane Punkte, die von einem weissen Hof umgeben sind und sich dadurch gegen das umgebende Gewebe scharf abheben. Solche Herde finden sich nur in der Rindensubstanz des Hinterhauptlappens, des Scheitellappens und der Centralwindungen, nicht im Marke oder im Centralgran.

Der milkroskopische Befund war folgender: Die Gefässe in dem Herde 
sind stark erweitert, dickwandig und vielfach ramificirt. Diese Gefässzweige sind theils offen, theils obliterirt. Verfolgt man die obliterirten Zweige weiter, so erblickt man gewöhnlich einen unregelmässig gestalteten, peripherisch stark mit Rundzellen infiltrirten Herd in der grauen Substanz, worin zahlreiche bräunlich gefärbte Körperchen sind. Das Lumen der kleinen Gefässe ist auch mit diesen Körperchen angefüllt. Diese sind nach Dr. Yamagiwa Eier des Distomum. Das umgebende, proljferirte und stark vascularisirte Bindegewebe ist mit Rundzellen infiltrirt. Es sind darin auch wohlgebildete Riesenzellen zu finden. Die Wandung des Gefässes ist verdickt und das erweiterte Lumen meist dureh Blut verstopft. Katzurada fand in einem Falle im Jinken Schläfenlappen zwei mit einander communicirende erweichte Herde, einer von Kindsfaustgrösse, der andere hühnereigross; ferner einen ebenso grossen Herd im Thalamus opticus. Alle diese Herde waren von einer bindegewebigen Kapsel umgeben, ibr Inhalt dickeitrig und mit zablreichen Lungenegeleiern.

In Anbetracht der wenigen Fälle, welche bis jetzt über diese eigenartige Erkrankung des Gehirns mitgetheilt sind, dürfte jeder nene Beitrag von Werth sein.

Der Krankheitsfall, den ich im Folgenden beschreiben werde, ist es in doppelter Hinsicht, einmal wegen der interessanten klinischen Erscheinungen, die er dargeboten, und ferner, weil die anatomischen Veränderungen, welche das Gehirn erlitten, in grösserer Ausführlichkeit beschrieben sind, als es bisher geschehen ist.

Der Krankheitsfall ist folgender:

Anamnese: Die 17 jährige Tochter eines Bauern aus der Provinz Kumamoto auf der Insel Kiushiu (zweit grösste Insel Japans), wo das Lungendistomum endemisch herrscht, stammt aus einer gesunden Familie. Ihre Eltern sind gesund und haben angeblich keine belastenden Krankheiten. Der Vater trinkt mässig; Geschwister sind nicht vorhanden. Die Geburt der Patientin verlief normal, ohne jede Operation. In der Kindheit hatte sie körperlich und geistig eine normale Entwicklung, und auch sonst hatte sie keine schwere Krankheit durchgemacht. Erst im September 1899 bekam sie ohne nachweisbare Ursache einen epileptischen Anfall. Dieser soll nach Angabe der Eltern folgendermaassen abgelaufen sein: Die Patientin bekam plötzlich Kopfschmerzen und Schwindel und darauf stellten sich bei ibr zuerst Zuckungen in der linken Gesichtshälfte ein. Nachdem diese an der linken Körperseite abwärts gegangen waren und das linke Bein ergriffen hatten, schlossen sich an die Zuckungen der linken Körperhälfte auch solche der rechten an, so dass der ganze Körper von clonischen Zucluungen ergriffen war, und sogleich stürzte sie bewusstlos hin. Der ganze Krampfanfall daverte ungefähr 2-3 Stunden, und ein solcher, wie oben beschrieben, soll ungefähr in einem Zeitraum von einem Monat 1-2 mal eingetreten sein. Seitdem klagte die Patientin von Zeit zu Zeit über Kopfschmerzen, linksseitiges Ohrensausen, Schwäche der linken Körperbälfte und über Unsicherheit beim Gehen. Nach Angabe der Eltern soll 
ausserdem bei der Patientin seit der Zeit der Anfälle die Intelligenz Einbusse erlitten haben, und besonders sei das Gedächtniss schwach geworden.

Status praesens: Am 3. October 1900 wurde die Patientin zum ersten Male untersucht. Sie ist von kleiner Statur und sieht 2--3 Jahre jünger aus, als sie in Wirklichkeit ist. Die Fettpolster sind gut entwickelt, die Haut ist blass und die Schleimhäute anämisch. Der Kopl ist normal gebaut, keine Deformation und keine Narben sind vorhanden. Die Patientin liagt über Kopfschmerzen, jedoch ist keine hyperästhetische Stelle beim Beklopfen des Kopfes zu finden. Der Gesichtsausdruck ist etwas blöde, die Augen- und Augenliderbewegung ist nicht gestört. Die linke Pupille ist mehr erweitert als die rechte, jedoch reagiren beide auf Liclit gut. Das Sehvermögen ist normal, ophthalmoskopisch findet man eine leichte Trübung an den Papillen. Geruch und Geschmack ist normal, ebenso ist auch das Mienenspiel ungestört. Das Gehörvermögen anf dem linken Ohre ist herabgesetzt; ferner ist linksseitiges Ohrensausen vorhanden. Das Trommelfell ist unverändert. Die Zunge und der Gaumen weisen leine Abweichungen auf; die Schlingbewegung ist intact; auch die Sprache ist nicht gestört. Am linken Arme der Patientin bemerkt man eigenartige Bewegungen, welche an diejenigen der Chorea erinnern. Diese Bewegungen werden durch Willensanstrengung auf wenige Grad herabgesetzt; beim Schlafen kommen sie vollständig zur Ruhe. Die Patientin kann mit jeder Hand gut greifen, tragen und sogar stricken, aber die Muskelkraft ist bedeutend schwächer im linken als im rechten Arm, während die Sensibilität ganz unverändert ist. Ebenso ist die Kraft des linken Beines etwas herabgesetzt, es ist aber auch bjer keine Alrophie und keine Sensibilitässtörung vorhanden. Patellarphänomen ist beiderseits gesteigert, besonders stark am linken Bein; ein Fussclonus jst links vorbanden; der Gang ist hinkend; keine Alaxie. Die elektrische Erregbarkeit ist nicht verändert. Die Herzdämpfung ist nach links verbreitert, $2 \mathrm{~cm}$ äber die Mammillarlinie; der Herzton ist rein; die Pulsfrequenz 80 pro Minnte; die Athmungsbewegung ist regelmässig, 17 pro Minute. Der Unterlappen der rechten Lunge erschallt gedämpft mit schwachem Athmungsgeräusch und selien feinblasigem Rasseln. Der Husten ist gering und Auswurf nur spärlich vorhanden, in welchem mikroskopisch nichts Besonderes gefunden wird; keine Hämoptoe rorhanden. Der Appetit ist gut und der Stuhlgang normal. Menstruation kommt bei ibr noch nicht vor. Die Körpertemperatur beträgt $36,4^{\circ} \mathrm{C}$. und das Körpergewicht 36 kilogramm.

Verlauf: Am 3. October wurde die Patientin im Hospital aufgenommen. In einigen Monaten nach der Aufnahme warde das allgemeine Befinden bedeutend besser, ibr Körpergewicht nahm zu und die Kopfschmerzen wurden geringer. Die Anfälle wurden sowohl nach der Anzahl, wie nach der Intensität der Krämpfe allmälig vermindert. Die choreaartige Bewegung des linken Armes war jedoch ununterbrochen fortgesetzt. Die motorische Störung der linken Körperhälfte wurde aber nach und nach immer stärker. Die Musculatur der linken Seite befand sich anfangs in schlaffer Lähmung, wurde aber nach und nach steif, besonders war dieses in der Hand sehr stark, und in Folge 
dessen wurden die Finger in absonderliche, athetosisähnliche Stellungen gebracht, und das linke Bein wurde durch die Contraction gebeugt, so dass die Patientin beim Gehen das erkrankte Bein nachschleifen musste.

Im November 1901 bekam sie wieder heftige Kopfschmerzen und hartnäckiges Erbrechen und ferner entleerte sie den Harn unwillkürlich. Krampfanfälle traten sehr häufig ein, dauerten aber manchmal nur ein paar Minuten. Ferner waren die allgemeinen Symptome auffallend verschlechtert. Thr Bewusstsein wurde geirübt und manchmal benahm sie sich unter dem Dämmerungszustande gegen die Umstehenden maniakalisch. Am 20. December 1901 wurde am Unterschenkel Oedem bemerkbar. Am 26. December fand der letzte Anfall auf dem Hofe statt, wobei sie auf das Pflaster stürzte und mit der Stirn stark aufschlug. Von diesem Anfall erholte sich die Patientin nicht mehr und endete nach einigen Stunden letal. Während der ganzen Krankheit schwankte die Körpertemperatur gewöbnlich zwischen $36^{\circ}$ und $36,5^{\circ} \mathrm{C}$.; manchmal stieg die Temperatur plötzlich auf $39^{\circ} \mathrm{C}$., wobei die Pulsfrequenz über 110 betrug, und dann traten auch meist Krampfanfälle auf. Pulsschläge waren meist 84 pro Minute vorhanden. Nicht selten fielen sie bis auf 54 , oder stiegen bis auf 112. Im Juli 1901 bekam sie an der linken Hand Herpes, welche aber nach zwei Wochen ganz geheilt wurde.

Sectionsbefund: Eine weibliche Leiche, 30 Stunden nach dem Tode. Der Rigor mortuum ist stark. Totenfleoke sind auf dem Rücken und auf der inneren Seite des Oberschenkels vorhanden. Es befinden sich an der Stirnund linken Patellargegend linsengrosse Unterhautblutungen. Das Unterhautgewebe und die Muskulatur in der Stirn- and Schläfengegend sind byperämisch. Die Sehädelknochen sind dünn und ebenfalls hyperämisch. Die Dura ist in der Stirngegend getrübt; die venösen Sinus sind mit Blut überfüllt. Beim Durchschneiden der Dura quillt eine grosse Menge subduraler Flüssigkeit hervor. Die Pia ist nicht verändert; die rechte Grosshirnhemisphäre scheint etwas voluminöser als die linke; Furchen und Windungen sind deutlich. $A n$ den Basilargefässen und an denen der Fossa Sylvii ist treine Veränderung aufgetreten. In der 2. Windung des rechten Stirnlappens zeigt sich eine hühnereigrosse fluctuirende blasenartige Neubildung und an der Basis des Gyrus Hippocampi eine taubeneigrosse fluctuirende Erhebung.

Schneidet man die Neubildung im Stirnlappen horizontal duroh, so sieht man im Innern einon hühnereigrossen Blutungsherd, welcher theils mit veraltetem, geronnenem Blute, theils mit frischem, flüssigem erfüllt ist. Die oberhalb des Herdes liegende Rindensubstanz reigt zur Erweichung und ist auch leicht brüchig. Der Linsenkern, der Sehhügel, die äussere und innere Capsel haben massenhafte, dicht nebeneinander stehende kleine Blutflecken, und in Folge dessen kann man ibre Structur nicht genau erkennen. Der rechte Seitenventrikel ist im Innern theils mit veraltetem, theils mit frischem Blut angefüllt. In dem Vorderhorn und im oberen Theile desselben ist die ausfüllende Blutmasse sehon zur Organisation übergegangen und mit der umgebenden Marksubstanz verwachsen. Auf einem sagittalen Schnitte der rechten Hemisphäre findet man in der Marksubstanz des Stimlappens zwei unregelmässig 
gestaltete Blasen resp. Cysten, welche von einer Wandung von hartem Bindegewebe umgeben sind und im Innern eine gelblich-bräunliche, dickflüssige Masse enthaiten. Die innere Fläche dieser Wandung ist von rauher Beschaffenheit und geht zum Theil mit der in Gewebsneubildung übergehenden Inhaltsmasse in Verwachsung über. Jede Cyste hat das Aussehen, als ob sie aus einer Gruppe kleinerer Cysten besteht, die miteinander durch kleine Durchlöcherungen communiciren. Die eine hat eine Tförmige Gestalt und ist 2,3 cm lang und $1 \mathrm{~cm}$ breit, während die andere $2 \mathrm{~cm} \mathrm{lang} \mathrm{und} 1 \mathrm{~cm}$ breit ist. In der Marksubstanz des Parietallappens unterhalb der Centralfurche befinden sich mehrere Cysten (von Linsen- bis Stecknadelkoptgrösse). Die Anzahl dieser Cysten beträgt auf einer Schnittfläche ungefähr über 30. Ebenso sind auch viele Cysten in der Marksubstanz des Temporal- und Occipitallappens vorhanden. Diese Cysten sind alle von gleicher Bauart. Die Marksubstanz, welche die Cysten umgiebt, zeigt eine milchig woisse Trübung. Schneidet man mit dem Messer diejenige Stelle der Marksubstanz durch, wo diese Cysten sich reichlich befinden, so bat man in der Hand das Gefüh], als ob man eine verkalkte Masse durchschneidet.

In der Hirnrinde (ausgenommen einige Stellen oberbalb des Blutungsherdes), im Thalamus opticus, im Nucleus lentiformis und in der Hirnbasis ist keine pathologische Veränderung wahrzunehmen.

Die linke Grosshirnhemisphäre ist vollkommen gesund, desgleichen auch die Hilnnerven. Der rechte Pyramidenstrang zeigt auf Durchschniten durch den Hirnschenkel weiter nach abwärts bis zum Rückenmark deutliche Träbung.

In der Lunge waren veraltete hämorrhagische Entzündungsherde und in der Pleura adhäsive Entzündung vorbanden. Aber weder Distomum noch Eier konnten sowobl makroskopisch wie mikroskopisch dort gefunden werden. In den übrigen Organer wurden Veränderungen, die mit Distomum zusammenhängen, nicht wahrgenommen.

Cysteninhalt im frischen Zustande.

Betrachtet man ein Tröpfchen des gelblich-bräunlichen, dicinfüssigen Inhaltes der Cysten im frischen Zustande unter einem mittelstarken Mikroskop, so sieht man viel Blutkörperchen, kernige Körperchen, Fetttröpfchen, Detritusmasse und vereinzelt Charcot-Leyden'sche Kristalle und ausserdem noch eine Menge von ovalen, gelblich hellglänzenden Gebilden. Diese Gebilde sind nach ihrem Aussehen als Fier von Distomum identificirt. Die Eier sind von einer dünnen (etwa 0,002-0,0035 mm dicken) Schale umbüllt und an einem Pole mit einem kleinen Deckel versehen. Der InhaIt der Eier zeigt verschiedene Configurationen. Bei den einen ist es nur eine granulirte Masse und bei den anderen mehrere kleinere oder grösserc Dotterkugeln. Im Ganzen sind sie den Eiern des Bothriocephalus latus ähnlich, aber weit grösser. Diese Eier sind zum Theil abgeplattet oder zerbrochen und kommen daher in verschiedenen Gestalten vor; in Form von Halbliugeln, Kugelsegmenten oder von abgedrückten Scheibenstückchen, in welchen der Inhalt meistens nicht mehr vorhanden ist. Nach ihrer Form und Beschaffenheit sind diese Eier nichts anderes als solche von Distomum pulmonale. Die Grösse der Eier ist sehr variabel. Meine 
Messungen über die durchschnittliche Grösse zeigen doch sehr nahe Uebereinstimmungen mit den Angaben verschiedener anderer Autoren. Ich werde in den unteren Zeilen Vergleiche anstellen.

\begin{tabular}{|c|c|c|}
\hline Name & Länge des Eies & Breite des Eies \\
\hline Baelz. & $0,08-0,1$ & 0,05 \\
\hline Leucart & 0,08 & 0,056 \\
\hline Braun & $0,12-0,13$ & $0,077-0,08$ \\
\hline $0 \tan i$ & 0,082 & 0,051 \\
\hline Katzurada & 0,035 & 0,057 \\
\hline Yamagiwa & 0,064 & 0,0406 \\
\hline Taniguchi & 0,0879 & 0,0562 \\
\hline
\end{tabular}

Die Schale ist gegen Einwirkung von Essigsäure, Schwefelsäure und Kalilauge resistent, aber durch concentrirte Salzsäure wird sie nach einiger. Minuten allmälig aufgelöst. Die Inbaltsmasse wird durch lange Einwirkung der Farbstoffe, besonders des Haematoxylins, blanschwarz gefärbt.

\section{Mikroskopische Untersuchung.}

Auf den Schnittflächen der aus den Centralwindungen der rechten Hemisphäre herausgenommenen und in Müll e r'scher Flüssigkeit gehärteten Stücken ${ }^{1}$ ) sieht man zurn grössten Theile in der unterbalb der Hirnrinde gelegenen Marksubstanz eine grössere Anzahl von Flecken(Fig. 1 und 2, Taf. IV), welche sich durch ihren hellgelblich bräunlichen, cholioladenartigen Farbenton von der anscheinend gesunden Umgebung scharf abgrenzen. Die Anzahl, Vertheilung und Form dieser Flecke ist sebr verschieden. An einzelnen Stellen sind sie verhältnissmässjg klein, liegen aber dafür sehr dicht zusammen; an anderen Stellen wiedernm haben sie eine ansehnliche Grösse, liegen aber dafür nur vereinzelt zu 2 bis 3 in einem verbältnissmässig grossen Territorium. Die grössten und am besten sichtbaren haben eine Länge von $2,0-2,5 \mathrm{~cm}$ und eine Breite von über $1 \mathrm{~cm}$. Die kleinsten, gerade noch sichtbaren, sind noch ungefähr kleinstecknadelkopfgross. Zwischen diesen beiden Extremen in der Grösse findet man ziemlich alle möglichen Zwischenstufen. Ebenso wie die Grösse dieser Flecke verschieden ist, so zeigen sie auch die mannigfachsten Configurationen; theils haben sie eine ovale Gestalt, theils sind sie ziemlich rundlich, oder sic sind in verschiedener Wejse länglich ausgezogen. Der grösste der sichtbaren Flecke, von über $2 \mathrm{~cm}$ Länge, hat z. B. eine schweifförmige Gestalt, indem er an seinem der Rinde zugekehrten Ende keulenartig. verdickt ist und nach dem anderen Ende schmal ausläuft und sich dabei schlängelt (Fig. 20). Andere etwas kleinere Flecke haben entweder eine keilförmige Gestalt (in der Form des lateinischen Q [Fig. 1b]), oder haben eine schmale schlangenförmige Gesłalt (Fig. 2b) und andere Formen mebr. Diese

1) Diese schon in Müller'scher Flüssigkeit gehärteten Stücke hat Herr Dr. Taniguchi im Laboratorium des Herm Dr. Jacobsohn mikroskopisch untersucht. 
eben geschilderten fleckigen Stellen werden fast überall von einem scharfen, dunkleren Rande nach der gesunden Hirnmasse lin umgrenzt. Die Flecke selbst werden von einer homogenen, hellgeibliohen Masse gebildet, welche in compacter Weiso in der Hirnsubstanz eingebettet liegt, und wolche im Innern vielfache, rerschieden grosse Einsenkungen (Fig. 1c und 2c) oder Durehlöcherungen aufweist (Fig. $1 \mathrm{~b}$ und $2 \mathrm{~h}$ ). Diese Einsenkungen resp. Durch¿öcherungen finden sich an den meisten Flecken; nur bei einzelnen scheint die Einbettungsmasse, welche diese Flecke ausmacht, undurchlöchert geblieben zu sein. Da auch bei den kleinsten Flecken solche Durchlöchernngen vorlommen, und da diese kleinen Flecke an einzelnen Stellen der Marksubstanz sehr zahlreich sind, so sieht die Schnittfläche an diesen Stellen wie siebartig durchlöchert aus. An einzelnen grossen Flecken sieht man an der homogenen Masse grössere Durchlöcherungen, so dass die Stellen das Aussehen ansehnlicher, vielfach zerklüfteter Cysten gewinnen (Fig. 1b), deren Wände mit der schon mehrfach genannten homogenen Masse ausgelileidet sind. Einzelne der in der Marksubstanz gelegenen Flecke erscheinen wie von einem dunklen Hof umgeben; dagegen zeigt bei anderen die umgebende Marksubstanz keine mit blossern Auge sichtbaren Veränderungen. Die Hirnrinde (Fig. 2r) tritt überall auf den Durcbschnitten deutlich bervor, grenzt sich gegen die Marksubstanz scharf ab und zeigt ihre gewöhnliche Configuration. Die Flecke sind in verschiedchen Abständen von der Hirnrinde gelagert, einzelne liegen der Rinde sehr nahe, andere sind dagegen in tieferen Schichten der Marksubstanz eingebettet.

Betrachtet man die mikroskopischen Schnitte mit blossem Auge (Fig. 3 und 4, Taf. IV), so zeigen sich die im Stüclie gesehenen Flecke nunmebr auch als Flecke (Fir. 3) oder meistens als Durchschnitte von hohlen Räumen (Fig. 4), welche von einom scharf abgegrenzten Saume umgeben sind (Fig. 3e u. 4e). Dieser Saum tritt auf allen Schnitten als eine scharfe, wellenartig geschlängelte, dicke Linie hervor, weiche sich durch eine intensire Färbung besonders heraushobt. Der Bohlraum, den diese Linie umgiebt, ist theils leer, theils mit einer homogenen Masse angefüllt, die entweder frei im Ranme liegt, oder an der Wand sich ansetzt (Fig. 40 ).

An einzelnen Stellen ist der innere Raum, welchen die scharf hervortretenden, eben geschilderten Linien umgeben, vollständig von einer homogenen Masse erfüllt, sodass diese Stellen dann ehen nicht als Cysten, sondern als Flecke in der Substanz erscheinen (Fig. 3c).

Diese Hohlräume und Flecke liegen in der Marksubstanz unterhalb der Hirnrinde, von letzterer ungefähr $1 / 2-1 \mathrm{~cm}$ entfernt. Die Grösse der Cysten, respective der Flecke beträgt am Schnitte gemessen bei der grössten 2,5-1,2 om und bei der mittleren $1,4-0,65 \mathrm{~cm}$ resp. $0,9-0,45 \mathrm{~cm}$. Noch andere sind etwa erbsengross, andere stecknadelkopfgross und die kleinsten sind schliesslich mit blossem Auge nicht mehr zu erkennen. Die Marksubstanz, welche die Cysten resp. Flecke umgiebt, erscheint auf den meisten Schnitten ziemlich unverändert, bis auf einen schmalen $(1 / 2-2 \mathrm{~cm}$ breiten) Saum (Fig. 3a), welcher die vorhin geschilderte, scharf hervortretende, geschlängelte Linie 
nach aussen umgiebt und sich ebenfalls anf sämmtlichen Präparaten durch eine intensive Färbung von der anscheinend gesunden Marksubstanz abbebt (Fig. 4a). Nur an einzelnen Stellen zeigt auch die Marksubstanz in weiterer Entfernung ein undeutliches fleckiges Aussehen, und diese Flecke zeigen einen gelblich bräunlichen diffusen Farbenton. An der Rinde, die oberhalb der Cysten und Flecke auf den Schnitten mitgetroffen ist, lassen sich mit blossem Augo nennenswerthe Veränderungen nicht erkennen.

Betrachtet man einen mikroskopischen Schnitt bei etwas stärkerer bis mittolstarker -Vergrösserung (Fig. 5, 6, 7, 8, Taf. IV), so sieht man noch deutlicher als vorher, dass diese Cysten resp. Flecke eine ausserordentlich scharfe Umgrenzungslinie haben, die meistens in leicht schlingenförmiger Linie verläuft (Fig. $7 \mathrm{e}, 8 \mathrm{e}$ ). Die Schlingen sind stellenweise recht flach und lang ausgedehnt, manchmal stark ausgebuchtet und zahlreich aufeinander folgend. An einzelnen Stellen ist die Ausbuchtung so stark und die ausgebuchtete Partie so eng, dass sie nur durch einen ganz schmalen Canal mit dem inneren Raum der ganzen Cyste in Zusammenhang steht. An einzelnen Stellen wiederum scheint auf dem Schnitt eine solche Ausbuchtung von dem Hoblraum der Cyste ein- oder vielfach abgeschnürt (Fig. 8i). Sind diese Schlingen sehr weit, die.Einmündungsstelle aber in die Cyste etwas eng, so erhält man auf dem Schnitt ein Bild mehrerer mit einander communicirender Cysten (Fig. 7). Die Cysten selbst sind zum grössten Theil mit einer theils gelblich bräunlichen (Fig. 5c), theils mattgrauen Masse angefüllt, welehe an vielen Stellen der genannten Umgrenzungslinie anliegt und nur an einzelnen Stellen auf dem Schnitte ausgefallen ist (Fig. $7 \mathrm{~b}$ ) resp. durch unregelmässig verlaufende Risse abgespalten ist (Fig. 5x und Fig. 60\%). Die Risse verlaufen zum grössten Theil der inneren Wand der Begrenzungszone parallel, zum Theil gehen sie aber mitten durch die Masse, welche die Cyste anfüllt, hindurch.

Die Begrenzungszone, welcbe die Cyste, wie vorher erwähnt. in schlingenförmigen Windungen umgiebt, hebt sich auf Präparaten, welche nach van Gieson gefärbt sind, durch ihre leuchtende violett-rothe intensive Fürbung ab (Fig. 6e). Sie stellt sich als ein Band von nicht unbeträchtlicher Breite dar. Nach innen von dieser bandförmigen Zone liegt eine hellere und schmälere Zone, die eine bellbräunliche Farbe hat und siebartig von weissen Flecken durchsetzt ist (Fig. $6 \mathrm{c}^{\circ}$ ).

Diese Zone ist schmäler als die vorber genannte; sie hebt sich als besondere Zone nur da $a b$, wo sie eine solche siebartig durchlöcherte Beschaffenheit zeigt. An anderen Stellen (Fig.5) hat sie eine mehr bräunliche Farbe und zeigt liaum eine Abgrenzung gegen dic, den inneren Raum der Cysten erfüllende vorher erwähnte Masse, in welche sie fast continuirlich übergeht. In dieser zuletzt genannten Zone liegt eine ausserordentlich grosse Anzahl von hellgelblich glänzenden, zum Theil bräunlichen Gebilden (Fig. 60). Diese Gebilde, welche sowohl nach ihrer Form, wie nach ihrem Aussehen als Eier von Distomumpulmonale (B a elz) identifieirt sind, liegen auch noch in grossen Haufen (Fig. $11 \mathrm{c}$, Taf. V) oder vereinzelt in der Masse, welche die Cysten erfüllt. Die vorher genannte dunkelrothe schlingenförmige Grenzzone der Cysten wird 
nun nach aussen noch von zwei, sich deutlich von einander abhebenden Schichten umgeben. Die eine, der Umgrenzungslinie zunächst liegende, sieht auf van Gieson-Präparaten hellbräunlich aus (Fig. 6f); sie hat ungefähr die gleiche Breite, wie die Umgrenzungslinie selbst und zeigt ein ziemlich gleichmässiges, aus lockerem Gewebe bestehendes, von gelblich gefärbten, rundlichen Körpern durchsetztes Gefüge. Die andere Zone (Fig. $6 \mathrm{a}, 7 \mathrm{a}$ ) ist die zerfallene und von Entzündung betroffene und in verschieden breitem Saume die Herde umgebende Marksubstanz. Diese zuletzt genannte Zone, welche ein maschenartiges Aussehen zeigt, ist von sehr zahlreichen, theils quer, theils längs getroffenen Gefässen durchsetzt, welche zum grössten Theil von Blut strotzen (Fig. $7 \mathrm{~g}$ ).

Betrachtet man den Inhalt der Cysten und die einzelnen Schichten, welche die Cystenwand selbst bilden, etwas genauer, so ergiebt sich folgendes:

\section{A. Cysteninhalt.}

Die vorher genannte gelblich bräunliche Masse, welche die Cysten ausfüllt (Fig. $5 \mathrm{c}, 6 \mathrm{c}, 7 \mathrm{c}, 8 \mathrm{c}$, Taf.IV, $11 \mathrm{c}$, Taf. V), besteht zum allergrössten Theil aus kleinen rundlichen Elementen, welche in ungeheurer Anzahl dicht nubeneinander gelagert, den Cystenraum erfüllen ( $\mathrm{Fig.} 9 \mathrm{c}$ ). In einzelnen dieser Cysten sieht man nichts weiter als diese zusammengeballt liegenden, kleinen rundlichen Zellen, welche sich nach van Gieson's Färbung theils gelblich, theils hellröthlich färben. In anderen Cysten, und zwar in solchen, deren Inhalt im Ganzen ein diffuses bräunliches Aussehen zeigt, namentlich da, wo ein Theil der Masse aus den Cysten herausgefallen ist, erkennt man an den herausgefallenen Stellen, dass hier ausser der Masse der Rundzellen zum Theil ganz dichtes, zum Theil noch lockeres Filzwerk, von feinen sich durcheinander verflechtenden dünnen Fasern, liegt, in welches die Rundzellen eingebettet sind. Dieses Flechtwerk kann man an einzelnen Stellen bis zu dem Saum, welcher, wie erwähnt, die Cysten schlingenartig umgiebt, verfolgen. Ausser diesen beiden genannten Bestandtheilen, nämlich den Rundzellen und dem Stroma, sieht man im Cysteninhalt theils vereinzelt, theils in kleinen Haufen grosse ovale, intensir gelblich glänzende Gebilde, die Eier von Distomum pulmonale. In der Mehrzahl der Cysten lässt sich ein Flechtwerk, in welchem die Rundzellen eingebettet sind, nicht erkennen, sondern die Rundzellen scheinen in einer ziemlich leicht liörnigen Masse eingebettet zu sein. Die Rundzellen, welche den Inhalt ausmachen, haben zum Theil die Grösse und Form von rothen Blutkörperchen, zum Theil sind sie auch etwas grösser. Die Contouren der runden Körperchen sind fast äberall nicht sehr deutlich. Ihr Inhalt hat ein leicht körniges Aussehen, ist aber sonst von etwas undeutlicher verwaschener Form. An van Gieson's Präparaten treten sie noch deutlicher hervor als an Kernfärbungspräparaten (Alaunhämatoxylin). An ersteren zeigen sie ein hellgelbliches Aussehen, an letzteren heben sie sich als ganz undeutliche, grangelbliche, rundliche Gebilde ab, welche keine deutliche Contour haben. Der allergrösste Theil dieses Cysteninhaltes bleibt also bei der Färbung mit Alaunhämatoxylin ungefärbt. und nur ein kleiner Theil der Rundzellen, welche den Inhalt ausmachen, zeigt die charakteristische dunkelblaue Färbung. Wäh- 
rend an einzelnen Cysten die grosse Masse der Rundzellen mit Alaunhämatoxylin ungeärrbt bleiben, giebt es andererseits Cysten, wo auch noch ein sehr erheblicher Theil eine dunkelblaue Färbung aufweist (Fig. 7 d).

In diesen Cysten bildet gewöhnlich der ungefärbte Theil die centrale und der gefärbte die peripherische Schicht der Inhaltsmasse. Die letztere Schicht grenzt direct an den breiten Saum an, welcher die Cysten umgiebt. Die Elemente dicser peripheren Schicht der Inhaltsmasse haben ungefähr die Grösse der weissen Bluthörperehen und liegen diebt gedrängt nebeneinander. Diese oben beschriebene Masse, welche aus rundlichen Gebilden besteht, macht im Ganzen den Eindruck ron Rundzellen, welche in Verfall begriffen sind. Die Masse verdichtet sich an der Peripherie der Cysten zu einer Art Wall, welcher an einzelnen Stellen schmal linienförmig und an anderen sehr breit und halbinselförmig in das Innere der Cysten hineingelagert ist (Fig. 7d). Dieser Wall tritt an Präparaten, die mit Alaunhämatoxylin gefärbt sind, als eine dunkelblau gefärbte Zone von ganz diffusem Aussehen deutlich hervor. An anderen Stellen zeigt dieser Wall nur einen schmutzig-grau-gelblichen Farbenton; an noch anderen Stellen ist diese Zone in 2 Striche getheilt, von welchen der inuere einen dunkelblauen und der äussere einen grau-gelblichgrünen Farbenton zeigt.

Betrachtet man den eben beschriebenen Wall unter stärkerer Vergrösserung, so sieht man noch dentlicher, dass sich hier der Cysteninhalt zusammengeballt hat. Während die gelblich-grüne Zone des Walls die gleiche Formation wie der Cysteninhalt selbst aufweist, liegen in dem blau gefärbten Strich dieser Zone runde Körper, welche das Hämatoxylin angenommen haben. An einzelnen Stellen zeigen die hier sichtbaren rundlichen Körper ein ganz unregelmässiges, verwaschenes Aussehen, und die Partie zeigt mehr einen detritusartigen Zerfall. In noch anderen Cysten sind die rundliehen Körper dieser Zone entweder rereinzelt oder in ausserordentlicher Anzahl scharf und deutlich ausgeprägt, liegen dicht gedrängt bei einander und verlieren sich allmälig in dem ungefärbten, ziemlich homogen aussehenden Inhalt der Cysten. Solche Anhäufungen von deutlich mit Hämatoxylin gefärbten Rundzellen liann man auch in Form ron kleinen Inseln mitten im Cysteninhalt erkennen. An einzelnen Orten sind die eben genannten Inseln durch Brücken mit einander verbunden, welche aus Rundzellen gebildet sind, und in dem dadurch gleichsam gebildeten Maschenraum liegen lieine Inseln des homogenen Cysteninhalts.

Der Wall, zu welchem sich die Peripherieschicht des Cysteninhalts zusammenballt, tritt auch an anders gefärbten Präparaten durch etwas dunklere Färbung vor derjenigen des Cysteninhalts hervor. An denjenigen Stellen, wo dieser Wall in die schlingenförmige Wandung der Cysten übergeht, und wo auch die Distomumeier reihenweise gelagert sind, erscheint derselbe in einzelnen Gegenden siebartig durchlöchert (Fig. $6 \mathrm{c}^{\star}$ ). In dieser siebartig durchlöcherten Zone ist der Cysteninhalt häufig von der Wand spaltrörmig abgerissen, wobei nur ein schmaler Saum mit der Wandung der Cysten in Verbindung bleibt. In dicsen Säutnen, die ein aufgefasertes wie gefranzt aussehendes Bild zeigen, liegen die Distomumeier (Fig. 60). Dieser Saum hat auf Präparaten, die nach 
Pal gefärbt sind, eine stahlblaue Farbe und besteht, unter starker Vergrösserung gesehen, zum Theil aus groben, schollig aussehenden Elementen, von denen manche becherartig geformt sind, zum Theil aus mehr rundlichen, linsenförmig gestalteten kleineren Gebilden. Alle diese stehen in ihrer Mehrzahl mit ihrer Längsseite senkrecht zum Querschnitt und ragen fransenförmig aufgefasert, sowohl in die Cystenmasse, als in die Cystenwand hinein.

Dieser zuletzt genannte Saum hängt, wie gesagt, mit der compacten, schlingenförmigen Cystenwand zusammen und geht continuirlich in letztere über (Fig. $9 \mathrm{e}^{\prime}$ ).

\section{B. Cystenwand.}

Die Cystenwand besteht nun aus einer inneren und einer äusseren $A b$ theilung.

Die innere ist die auf allen Präparaten am markantesten hervortretende Zone, und zwar tritt sie dadurch so besonders hervor, dass sie auf allen Präparaten sehr intensiv gefärbt ist und sich durch ihren Farbenton von allen anderen Zonen deutlich abhebt, ferner dass sie überall gleichmässig breit ist, und dass man an ihr am besten die schlingenförmige Umgrenzungslinie der Cysten verfolgen kann. Nur an einzelnen Stellen erscheint die Zone breiter und unregelmässiger, und zwar immer an solchen Stellen, wo die Wand der Cyste nicht ganz quer, sondern schräg getroffen ist, resp. wo der Schrägschnitt durch Verschiebung der Wand reranlasst ist.

Diese gleichmässig in ihrem Farbenton stark hervortretende Zone hat auf Präparaten, die nach van Gieson gefärbt sind, einen rothen Farbenton (Fig. 6e). Auf Präparaten mit Eosin-Hämatoxylin ersoheint sie hellrosa (Fig. $8 \mathrm{e}$ und $9 \mathrm{e}$ ), and auf Präparaten, die mit Alaun-Hämatoxylin allein gefärbt sind, hat sie einon ganz hellen Farbenton (Fig. 7 e). Ebenso erscheint sie ganz hell auf Präparaten, die nach Pal's Verfahren behandelt sind. Dunkelblau bis violett erscheint sie wiederam auf Präparaten, die mit Weigert'scher Färbung zur Darstellung der elastischen Faser gefärbt sind (Fig. 11 e Taf. V). Auf allen Präparaten hebt sie sich also, wie aus den angeführten Beispielen ersichtlich ist, durch einen intensiv dunklen oder durch einen intensiv hellen Farbenton deutlich von den anderen Zonen ab. Betrachtet man nun dieso schlingenförmige Zone unter starker Vergrösserung auf Kernfärbungspräparaten (Fig. 9e), so unterscheidet sie sich bezüglich der in ibr liegenden Kerne von der aussen vor ibr liegenden Zone sehr wesentlich. Im Gegensatz zur äusseren Zone (Fig. 9f) liegen die Kerne in ihr viel spärlicher, also viel mehr zerstreut. Diese sind auch viel kleiner und baben ofters eine langgestreckte, stäbchenförmige Gestalt. Diese Karne liegen in zelligen Gebilden ron langgestreckter, spindelförmiger Gestalt, wobei der Zellleib sich an seinen beiden Enden spitz auszieht resp. in einen spitzen Faden ausläuft. Die zelligen Gebilde von lanzettförmiger Gestalt liegen zum Theil dem Querschnitte des Saumes parallel, zum Theil quer odor schräg zu letzterem. Während sie in der Mitte der Schicht oft ziemlich gedrängt aneinander liegen, lockern sie sich sowohl in der Peripherie mach dem Innern, als auch nach aussen hin (hier aber nicht so 
stark). In der inneren lockeren Schicht haben die Kerne resp. deren Zellen oft eine besonders langgestreckte Form und zeigen hier besonders eine zum Querschnitt des Gefässes schräge Lage. Von dieser lockeren Zone erstrecken sie sich noch als Aụsläufer zahlreich in die saumartige Zone, in welcher die Distomumeier liegen (Fig. 9 $\mathrm{e}^{\varsigma}$ ). Die eben beschriebenen lanzettförmigen Zellengebilde haben grosse Aehnlichkeit mit der Gestalt derjenigen zelligen Gebilde, welche man in den Wandungen der Gefässe findet (vgl. Fig. 12e und $13 \mathrm{~g}$ Taf. V).

Weiter peripheriewärts von dieser inneren Schicht liegt in der den ganzen pathologischen Herd umfassenden Wandung eine andere, in die Marksubstanz oft breit hineindringende äussere Schicht der Cystenwandung, welche auf Präparaten mit van Gieson's Färbung (Fig. $5 \mathrm{f}$ und $6 \mathrm{f}$ ) röthlich bräunlich, auf Kernfärbungspräparaten (Fig. $7 \mathrm{f}$ und $8 \mathrm{f}$ ) dunkelviolett erscheint und sich bei schwacher Vergrösserung als ein lockeres Faserwerk darstellt, in welchem an verschiedenen Stellen mehrere gefässartige Bildungen verlaufen. Das Faserwerk der äusseren Schicht wird umso lockerer, je mehr es sich nach der Peripherie zu erstreckt, und es dringt weitverzweigt in die Marksubstanz hinein; schliesslich verschwindet es allmälig in der die pathologischen Herde in schmalem Saume umgebenden Zone degenerirter Markmasse (Fig. 5a). Betrachtet man diese Schicht auf Präparaten, die mit Alaunhämatoxylin gefärbtsind bei schwacher Vergrösserung, so stellt sie sich als eine bläuliche, streifenförmige Zone dar, welche gleichsam einen scharfen äusseren Abschluss der Cystenwand repräsentirt (Fig. $7 \mathrm{f}$ und 81). Bei starker Vergrösserung sieht man, dass diese äussere Schicht ausser den lockeren Fasern aus dichtgedrängt aneinander gelagerten rundlichen oder länglich ovalen Kernen bestebt, zwischen welchen auch hier und da einmal wenige spindelförmige liegen (Fig. 9f). Die Mehrzahl dieser Kerne hat dàs Hämatoxylin intensiv angenommen, so dass sie stark violett erscheinen, eine nicht unbeträchtliche Zahl ist aber nur matt gefärbt oder auch ganz ungefärbt geblieben. Was ihren feineren Bau anbetrifft, so zeigen die Kerne selbst bei Oelimmersion betrachtet ein ziemlich homogenes Aussehen. Hier und da sieht man im einzelnen eine fein- oder groblïrnige Structur; eine grosse Anzahl stellt sich in solcher Formation dar, als ob ein Theilungsprocess vorliegt. Ihre Grösse entspricht etwa derjenigen vom Lymphkörperchen resp. weissen Blutkörperchen.

Diese violett gefärbten Kerne liegen in zelligen Gebilden von nur mässigem Umfang und von wechselnder Gestalt. Die Zellkörper färben sich mit Eosin matt rosa und zeigen fast gar keine Structur (Fig. 9f). Diese Elemente liegen, wie gesagt, in der äusseren Zone so dicht zusammen, dass sie auf Präparaten mit Alaun-Haematoxylin einen dunklen Strich bilden (Fig. 7f); nach innen und aussen zu (Fig. 9) lockern sie sich etwas. Auf Präparaten, die nach van Gies on gefärbt sind, sieht man, dass ein grosser Theil der oben genannten Gebilde einen bräunlichen Farbenton zeigt, als ob sie mit Blutfarbstoff imprägnirt wären, resp. als ob ein grosser Theil veränderter Blutkörperchen eingelagert wäre (Fig. 6f). Das Grundgewebe dieser Zone bildet ein lockeres Maschenwerk, welches den gleichen Bau und Farbenton wie das 
adventitielle Gewebe der Gefässe hat. Oft kann man einen directen Zusammenhang dieses Gewebes mit dem der'sehrnahe liegenden Gefässe erkennen (Fig. 10`). In dieser Zone liegen schliesslich einzelne schmale Ausbuchtungen der Cystenwand, die, oberflächlich betrachtet, als Gefässdurchschnitte erscheinen können. Das Lumen dieser Ausbuchtungen, in welchem oft ein bis zwei Distomumeier liegen, steht entweder mit dem Lumen der Cyste noch in directem Zusammenhang, oder aber diese Ausbuchtungen sind vom Schnitte so getroffen, dass sie vollkommen von der Cystenwand abgeschnürt erscheinen (Fig. 8i). Die Wandung dieser kleinen Abschnürungen zeigt dieselben Zonen von gleichem Bau, wie die eigentliche Cystenwand selbst (Fig. 12, Taf. V)). Die Elemente der einzelnen Zonen der Wandung dieser abgeschnürten Theile zeigen, wenn man ein daneben liegendes Blatgefäss mit ihnen vergleicht (Fig. 12 und 13) sehr grosse Aehnlichkeit mit den Wandungsverhältnissen des letzteren. Die Färbung der Cystenwandung nach der Weigert'schen Färbung zur Darstellung der elastischen Fasern ergab Gebilde, welche bei schwacher Vergrösserung viel Aehnlichkeit mit solchen Fasern zeigten. Bei starker Vergrösserung jedoch erwiesen sich diese Gebilde zum grössten Theil als Lücken. An einzelnen Stellen war auch bei sehr starker Vergrösserung eine Entscheidung, ob es sich um elastische Fasern oder um Lü̈cken handelte, nicht sicher zu treffen.

Die Dicke der beschriebenen Cystenwandungen ist sehr verschieden; bei den grössten, über $25 \mathrm{~mm}$ breiten Cysten, und bei den mittelgrossen beträgt sie ungefähr $1,2-0,8 \mathrm{~mm}$. Der innere Saum, welcher direct mit der Inhaltsmasse der Cyste in Berührung kommt, und wo die Distomumeier reihenweise an der Wand nebeneinander steben, beträgt $0,18 \mathrm{~mm}$, die mittlere resp. innere Schicht $0,40 \mathrm{~mm}$ and die äussere Schicht $0,25 \mathrm{~mm}$ Dicke. Selbst bei den kleinsten, deren Lumen kaum $0,4 \mathrm{~mm}$ betragen, hat die Cystenwandung eine Dicke von $0,3 \mathrm{~mm}$, worunter der innere Saum $0,07 \mathrm{~mm}$, die mittlere Schicht $0,14 \mathrm{~mm}$ und die äussere $0,10 \mathrm{~mm}$ betragen.

Die die Cystenwand umgebende weisse Marksubstanz weist, wie schon erwähnt, in einem schmaleren oder breiteren Umkreise um die Cysten Veränderungen auf und rerliert sich dann peripherwärts in das gesunde Mark (Fig. 3a, 6a, 7a, 8a). Diese Veränderungen der die Cysten umgebenden Marksubstanz bestehen einmal primär in einer diffusen Vermehrung von Rundzellen, die locker im Gewebe zerstreat liegen und aus einer sehr starken perivasculären Rundzellleninfiltration (Fig. $7 \mathrm{~g}$ und $13 \mathrm{~g}^{\prime}$ ) mit ausserordentlicher Wucherung des adventitiellen Gewebes (Fig. 10g') und Austritt von Exsudatmasse, welche in compacter Masse die perivasculären Räume erfüllt (Fig. 10t), welche aber auch in Form von grösseren Kugeln (Fig. 10 t') sich in der Markmasse abgelagert haben. Dass diese Kugeln höchst wahrscheinlich solche abgeschnürten Theile von Exsudatmasse darstellen, geht daraus hervor, dass sie von gleicher Farbe and von gleichem homogenem Aussehen sind, und dass sie an vielen Stellen in directem Zusamenhange mit der die perivasculären Räame erfüllenden Masse stehen. Nach der Weigert-Pal'schen Methode und der Marchi'schen Methode bleiben sie ganz ungefärbt. Diese Exsudatmasse hat viele Nertenfasern gleichsam umscheidet, wenigstens sieht man im 
Innern der kugelförmigen Bildungen noch oft einen Querschnitt eines Axencylinders mit undeutlicher Markscheide. Die secundären Veränderungen der die Cysten umgebenden Marksubstanz bestehen im Zerfall des Markes, welches zum grössten Theil in diesen Zonen gesohwunden ist (Fig. 3a). Bei starker Vergrösserung lassen sich noch vereinzelte, matt violett gefärbte Markkugeln erkennen. Präparate, nach Marchi'scher Methode hergestellt, ergaben keine wesentlicben Veränderungen der Nervenfasern in der Marksubstanz. Die Gefässe dieser degenerirten Markmasse zeigen nicht nur Verdichtungen der Adventitia, sondern auch solohe derMedia, und alle sind mitBlutkörpern strotzend gefüllt.

Von sonstigen Veränderungen sind noch zu erwähnen: 1. Alterationen der Hirnrinde und Marksubstanz. 2. Veränderungen der Pyramidenbahn der betreffenden Hemisphäre.

Was die zuerst genannten Veränderungen der Hirnrinde und Marksubstanz anbetrifft, so bandelt es sich, soweit nach den vorliegenden Prạpparaten geurtheilt werden kann, um eine dentliche Kernvermehrung in der Rinde und in dem darunter gelegenen Marke im Bereiche der pathologischen Herde. Die Kernvermehrung ist an erster Stelle perivasculär, wie sie, je nachdem das Gefäss längs oder quer getroffen ist, in schmalen Längsstrichen oder in kleinen isolirten rundlichen Haufen sich darbietet. Ausserdem findet man aber eine diffuse Kernvermehrung in der ganzen Rinden- und Marksubstanz ausgeprägt. Häufig sieht man zwei Kerne noch im Zusammenhang mit einander, die im Begriff sind, sich zu theilen. In den perivasculären Räumen trifft man hier und da vereinzelt ein bis zweiKerne; die meisten jenerRäume sind frei von Kernen. Die Ganglienzellen der Rinde zeigen, soweit man dieses nach van Gies on' schen Präparaten beurtheilen kann, lieine wesentlichen Veränderungen sowohl der Form als auch der Configuration nach. Sie zeigen deutliche Fortsätze und Kerne und sehen weder gequollen noch atrophisch aus. Auch in diesen Theilen und im Piagewebe sind die Gefässe stark mit Blut gefüllt.

Was die Veränderung der Pyramidenbahn anbetrifft, so fand sich (nach brieflichen Mittheilungen des Collegen Herm Dr. Mishumi, der diesen Theil in Japan untersucht hat) eine deutliche Degeneration der Pyramidenbahn der rechten Seite, herabsteigend von der inneren Kapsel bis zur Medulla spinalis.

\section{Epikrise.}

Der soeben beschriebene Fall ist sowohl in anatomischer wie in klinischer Beziehung von hohem Interesse.

In anatomischer Hinsicht handelt es sich um entzündliche Erweichungsherde, welche an mehreren Stellen im Marklager der rechten Grosshimhemisphäre nicht weit entfernt von der Rinde entstanden sind. Diese Herde sind erzengt durch Eier des Lungenegels, welche in jedem Herde in Menge angetroffen wurden. Die Herde selbst stellen sich auf dem Schnitt entweder als Flecke erweichter und zerfallerer Substanz dar, 
welche von einer derben Kapsel eingeschlossen ist, oder sie stellen sich als einfache Cysten dar, indem ein Theil der Inhaltsmasse ausgefallen ist, oder schliesslich erscheinen sie in Form communicirender Hohlräume. Während die erweichte Inhaltsmasse an den Flecken und Cysten, wahrscheinlich je nach dem Alter des Herdes, ein wenig verschieden ist, indem mehr oder weniger zerfallene Blutreste in ihnen enthalten sind, im Uebrigen aber überall aus zerfallenen amorphen Körpern bestehen, welche die Farbstoffe nur minimal annehmen, zeigt die Wand, welche diese Inhaltsmasse umschliesst, überall den gleichen Bau. Sie besteht im Wesentlichen aus zwei breiten Schichten, einer mehr spindelzelligen inneren und einer überwiegend rundzelligen äusseren Schicht. Während die innere Schicht überall, sobald sie senkrecht getroffen ist, einen gleichmässig breiten Querschnitt zeigt, ist die äussere Schicht ungleichmässig. An vielen Stellen erkennt man, dass diese änssere Schicht mit dem adventitiellen Gewebe der in der Nachbarschaft gelegenen Gefässe im Zusammenhang steht. Sie verliert sich ansserdem langsam in der die Herde umgebenden Marksubstanz, welche in einem gewissen Umkreise deutliche Zeichen der Entzündung aufweist. Die innere Schicht der Wand zeigt ausser ihrer Zusammensetzung ans spindelförmigen Gebilden noch das Charakteristische, dass sie an vielen Herden einen schlingenförmigen Verlauf hat, wobei die Schlingen bald stark gekrümmt und zahlreich nebeneinander liegen, bald wiederum flacher sind und seltener aufeinander folgen. Obwohl sich in der Wand der Herde nicht mit voller Sicherheit elastische Fasern nachweisen liessen, so zeigte sich doch in ihrem Bau eine grosse Aehnlichkeit mit demjenigen von Gefässen. Sebr deutlich erhellt dieses aus dem Vergleich der Fig. 12 und 13, Taf. V von denen die eine den Durchschnitt der Wand eines Herdes, die andere den Durchschnitt der Wand eines daneben liegenden Gefässes darstellt. Dass die äussere Zone der Wand des Herdes dieselbe Structur wie das adventitielle Gewebe der Gefässe hat, geht aus dem Vergleiche der Elemente hervor, die in beiden aus Rundzellen und aus lockerem Fasergewebe besteht. Aber auch die Aehnlichkeit der inneren Schicht der Wand der einzelnen Herde mit den imneren Schichten der Gefässwand ist wohl eine sehr erhebliche; wenigstens hat ein grosser Theil der in der inneren Zone der Herdwandung gelegenen Kerne und Zellen grosse Aehnlichkeit mit den Kernen und Zellen glatter Muskelfasern. Die Wandung, welche die erweichten Herde, in denen die Distomumeier liegen, ungiebt, stellt demnach unserer Auffassung nach nur eine veründerte Gefässwandung dar. Dass sie nicht etwa die Wand des ins Gehirn eingewanderten Parasiten darstellt, geht schon daraus hervor, dass nirgends irgend 
welche Reste dieses Parasiten (mit Ausnahme der Eier natürlich) in den Herden gefunden wurden, obwohl eine Anzahl dieser Herde dem Anscheine nach wohl noch verhältnissmässig jungen Datums waren. Es könnte also nur noch in Frage kommen, ob die Wand der Herde lediglich aus gewuchertem Bindegewebe besteht, durch dessen Wucherung sich eine Kapsel um die in das Gehirn gedrungenen Fremdkörper gebildet hätte. Wenn diese letztere Möglichkeit uns auch nicht ganz ausgeschlossen zu sein scheint, so halten wir doch die vorher genannte Ansicht für die wahrscheinlichere.

Hiernach erscheint es uns, als ob die Herde in unserem Falle in folgender Weise zu Stande gekommen sind.

Von den Mutterthieren, die wabrscheinlich in der Lunge gesessen haben, sind zu verschiedenen Zeiten grosse Schwärme von Eiern auf embolischem Wege ins Gehirn gelangt und haben hier an verschiedenen Stellen des Marklagers unterhalb der Rinde eine grosse Zahl kleinerer Gefässe verstopft. Durch die Hineinschleuderung grosser Mengen von Eiern und durch die gleichzeitig damit verbundene Blutfülle (die auch durch Rückstauung eingetreten sein kann) hat sich das Lumen dieser Gefässe stark gedehnt. Der im Lumen enthaltene, die Distomumeier bergende Thrombus ist in gewöhnlicher Weise zerfallen; die Fremdkörper übten einen dauernden Reiz auf die dünne Gefässwandung aus und führten zur Proliferation seiner Wandung und zur Wucherung des adventitiellen Gewebes, wobei gleichzeitig die elastischen Fasern zerstört wurden. Oder aber durch Verstopfung vieler kleiner Gefässe in einem Bezirk bildeten sich hämorrhagische Infarcte. Das Centrum dieser Infarcte verfiel der Nekrose, und die den Infarct einschliessenden Gefässwände proliferirten durch den Reiz der im Innern gelegenen Eier und bildeten so die Wandung der stark schlingenförmigen Kapsel resp. die Wand mehrerer mit einander communicirender Höhlen.

Neigt man der Ansicht zu, dass die Wand der Herde nur aus gewuchertem Bindegewebe besteht, so muss man sich vorstellen, dass die Eier aus den Hirngefässen frei in die Hirnsubstanz gedrungen sind, und dass sich nun um sie eine Entziundungskapsel gebildet hat. Diese Möglichkeit würde bei Invasion des Lungenegels selbst ins Gehirn nicht von der Hand zn weisen sein, da Aebnliches wohl in den Primärherden nachgewiesen ist, erscheint aber in den Fällen wie dem unsrigen unwahrscheinlich.

Damit stimmen auch die Ansichten von Yamagiwa und Katzurada überein, welche die besten anatomischen Untersuchungen über Lungenegelerkrankung angestellt haben. "Verfolgt man", sagt Yamagiwa in seinem Fall, „die obliterirten Zweige der Rindengefässe (des 
betreffenden Bezirkes, wo die pathologischen Herde sitzen) weiter nach der tieferen Schicht der grauen Rinde, so erblickt man gewöhnlich einen unregelmässig gestalteten peripherisch stark mit Rundzellen infiltrirten Herd in der grauen Substanz, worin zahlreiche schwach bräunlich gefärbte Körperchen (Eier) sich finden, oft ist das Lumen kleinerei Gefässe mit solchen Körperchen gefüllt. Das umgebende proliferirte und stark vascularisirte Bindegewebe ist mit Rundzellen infiltrirt. Die Wandung der Gefässe ist verdichtet und das erweiterte Lumen meist mit Blut verstopft."

Yamagiwa konnte also, wie aus dem Gesagten hervorgeht, die Gefässe direct verfolgen, wie sie in den tieferen Rindenschichten in die pathologischen Herde übergingen. Die Abbildung, welche Yamagiwa in seinem Falle von solehem Herde mit umschliessender Wand giebt, stimmt mit dem Aussehen der Wandung in unserem Falle vollkommen überein.

Sehr wichtig erscheint auch die Ansicht, welche Katzurada über die Wandung, die sich um die Lungenegel bildet, äussert, weil dieser Autor sehr viele Fälle anatomisch zu untersuchen Gelegenheit hatte. Sein Material, schreibt er, hätte ihm sichere Beispiele geliefert, wo eine gewisse Zabl von Lungenegelhöhlen in Erweiterungen von Bronchien entstanden waren. Der Haupttheil der Höhlenwand besteht auch hier aus fibrösem Bindegewebe, von kleinzelliger Infiltration begleitet, ausserdem eine sich in Unterbrechungen hinziehende Schicht von glatten Muskeln. In anderen Höhlen konnte Katzurada keine Beziehungen zu den Bronchien entdecken. Im Gehirn fand Katzurada nur in einem Falle durch Lungenegel veranlasste Erweichungsherde. Diese waren mehr oder weniger von entzündlicher Infiltration begleitet und von einer bindegewebigen Membran eingekapselt. Vollständige Würmer konnte Katzurada in seinen Herden nicht entdecken, dagegen liessen in Masse vorkommende Eier seiner Meinung nach daranf schliessen, dass ausgebildete Würmer sich dort befunden haben mussten. Was die Entstehungsweise der Herde anbetrifft, so ist Katzurada im Zweifel darüber, ob durch Embolie des Wurmkörpers in ein Hirngefäss die anämische Nekrose des betreffenden Gefässbezirkes hervorgerufen war oder dadurch, dass die Wurmkörper direct die Hirnsubstanz zerstörten.

Wir sind der Ansicht, dass in den Fällen, wo ein Distomum selbst im Gehirn nicht wahrgenommen wird, sondern sich nur massenbafte Eier in den Herden finden, diese Eier auf embolischem Wege ins Gehirn gelangt sind, und dass bei der Bildung der sich um die Herde bildenden Kapsel die von den Eiern verstopften Gefässwandungen eine wesentliche Rolle spielen. Dass sich um die Herde in einem gewissen 
Umkreis eine exsudative Entzündung bildet, welche das Nervengewebe zerstört, ist ziemlich von allen Autoren angegeben und zeigt sich auch in unserem Falle überall sehr deutlich.

Nicht uninteressant scheint uns die Deutung der grossen sich in der eben erwähnten Entzündungszone befindlichen rundlichen Kugeln von homogener Beschaffenheit als abgesprengte Exsudatkugeln, weil wir glauben, dass diese Gebilde in vielen Fïllen von Encephalitiden wohl als morphologische Elemente aufgefasst worden sind.

Was nun die klinischen Erscheinungen in diesem Falle anbetrifft, so lassen sie sich aus den anatomischen Veränderungen zur Genüge erklären. Es sind im Wesentlichen Krampfanfälle, welche das Krankheitsbild beherrschen, die nach ihrem Verlaufe und ihrer Art als corticale Epilepsie zu bezeichnen sind. Die gleiche Erscheinung fand sich auch in fast allen Fällen von Distomumerkrankung des Gehirns, sowohl in solchen, wo, wie in Fällen von Yamagiwa, die Herde nur in der Rinde sassen, als auch in den anderen Fällen, wo die Herde im subcorticalen Marklager ihren Sitz hatten. In den letzteren muss man wohl annehmen, dass der von den Herden ausgeübte Reiz sich auf die Rinde fortgepflanzt hat und bei Erreichung einer gewissen Höhe zum Ausbruch des Anfalles geführt hat.

Was diesen Fall auch in klinischer Hinsicht heraushebt, ist, dass neben der' Jackson'schen Epilepsie auch noch Chorea in den rechten Extremitaten bestanden hat, und dass die Chorea sich im weiteren Verlaufe der Krankheit in Athetose umwandelte. Einen ähnlichen Fall beobachtete Bernhardt. Als anatomisches Substrat der Chorea können in unserem Falle gleichfalls die im subcorticalen Mark unterhalb der Centralwindungen gelegenen Herde angesehen werden, indem sie durch ihren Reiz auf viele Pyramidenfasern die Bewegungsstörungen veranlassten; es können aber auch als Ursache der Chorea die Kerninfiltrationen angesehen werden, die sich in der Rinde und im darunter gelegenen Marke der motorischen Region gefunden haben. Letzterer Befund würde mit demjenigen grosse Aehnlichkeit haben, welcher in der letzten Zeit in Fällen von chronischer Chorea erhoben wurde und als Fncephalitis chronica disseminata bezeichnet worden ist.

Sehr interessant ist num der Umstand, dass im Verlaufe der Krankheit mit zunehmender Schwäche und Eintritt von Spasmus in den auch von den Krämpfen befallenen Extremitäten die choreaartigen Bewegungen sich in athetotische umwandelten.

Die Choreabewegungen sollen nach der älteren Theorie hervorgerufen werden durch Reize, welche fast fortdauernd die motorischen Fasern in ihrem Verlaufe hauptsächlich im subcorticalen Mark resp. in 
der Region der centralen Ganglien treffen. Nach der von v. Monak ow aufgestellten Theorie dagegen soll dieser Reiz zunächst auf sensible Fasern der Regio subthalamica wirken, welche dann ihrerseits wiederum durch Vermittlung der Rinde motorische in Erregung versetzen. Die Entscheidung, welche von beiden Theorien die richtige ist, Iässt sich schwer treffen.

Ohne ausführlich auf alle Gründe einzugehen, welche zu Gunsten der einen oder der anderen Theorie angeführt werden, sei hier nur bemerkt, dass dieser Fall mehr zu Gunsten derjenigen Theorie spricht, welche in der Reizung der motorischen Fasern selbst die Ursache der choreatischen Bewegung sieht. Die pathologischen Herde sassen hier unterhalb der Centralwindungen. Sie führten weder im Anfang noch im weiteren Fortschreiten, selbst als durch dieses eine grosse Menge von Fasern zerstört wurde, klinisch zu Veränderungen der Sensibilitït. Letzteres aber könnte man wohl erwarten, wenn man annimmt, dass der die Chorea erzeugende Reiz zunächst die sensiblen Bahnen treffe und erst von diesen auf die motorischen übertragen werde. Dagegen stellte sich mit dem Fortschreiten des Krankheitsprocesses eine spastische Lähmung ein, und mit dem Zunehmen der Spasmen verwandelten sich die vorher choreatischen Bewegungen in athetotische um. Als anatomischer Ausdruck der spastischen Lähmung wurde postmortal eine Degeneration der Pyramidenbahn gefunden. Aus dem Fehlen sensibler Ausfallserscheinungen trotz Zerstörung einer grossen Zahl von Nervenfasern im subcortical unter den Centralwindungen gelegenen Varklager und aus der Umwandlung der choreatischen Bewegungen in athetotische gemäss dem Fortschreiten der Zerstörung der Markfasern lässt sich vielleicht doch eher folgern, dass die choreatischen Bewegungen direct durch Reizung motorischer Fasern bedingt werden.

Zum Schlusse spreche ich Herrn Privatdocenten Dr. L. Jacobsohn für die gütige Unterstützung, die er meiner Arbeit zugewendet hat, und Collegen Herrn Dr. Mishumi, Vorsteher des städtischen pathologischen Instituts zu Kumamoto, für die treundliche Zuschickung des Materials und Sectionsprotokolls meinen aufrichtigsten Dank aus.

\section{Erklärung der Abbildungen (Taf. IV und V).}

Figur 1 und 2. Ansicht der in der Marlsubstanz unterhalb der Hirnrinde gelegenen Flecke resp. Cysten an Stücken, welche in Müller'scher Flüssiglieit gehärtet sind (normale Grösse). b) Cyste. c) Flecke. m) Marksubstanz unter der Rinde. r) Rinde. 
Figur 3. Fleck in der Marksubstanz unterhalb der Rirde (normale Grösse). Färbung nach Pal. a) Zerfallene Marksubstanz, welche den Fleck in schmaler Zone umgiebt. e) Schlingenförmige Wandungen, welche den Fleck umgeben. Die übrigen Bezeichnungen wie in Figur 1 und 2.

Figur 4. Cyste unterhalb der Rinde. Färbung nach van Gieson (normale Grösse). c) Inbaltsmasse der Cyste, zum Theil herausgefallen. Die übrigen Bezeichnungen wie vorher.

Figur 5. Frischer Herd in der Marksubstanz unterhalb der Rinde. Färbung nach van Gieson. Vergr. 1:5. x) Spalten in dieser M'asse. e) Die die Masse umgebonde Wandung. f) Aeussere, aus lockerem Gewebe bestehende Schicht der Wand. a) Marksubstanz. g) Gefässdurchschnitt.

Figur 6. Ein kleiner Abschnitt einer Cyste (Inhaltsmasse und Wandung) bei mittelstarker Vergrösserung. Färbung näch van Gieson. Vergr. 1:25. a) Marksubstanz in der Nähe der Cyste. f) Aeussere, aus Rundzellen und lockerem Gewebe bestehende Zone der Cystenwand. e) Innere, gleichmässig breite und schlingenförmig laufende Zone der Cystenwand. c) Inhaltsmasse der Cyste. c ) Peripherischer Theil der Inbaltsmasse, welcher mit der Wand in continuirlichem Znsammenhange steht, und sich an einzelnen Stellen von der centralen Inhaltsmasse abgespalten hat. o) Eier von Distomum; reihenweise in dieser peripherischen Zone lagernd.

Figur 7. Durchschnitt durch mehrere nahe bei einander gelegene und mit einander communicirende Cysten. Färbung mit Alaunhaematoxylin. Vergröss. 1:5. a) Marksubstauz in der näheren Umgebung der Cysten. b) Lumen der Cysten. d) Wallartige Verdickung der Inhaltsmasse an der Peripherie. e) Innere, duroh Alaunhaematoxylin hell erscheinende Zone der Cystenwand (aus spindelförmigen Zellen und Kernen bestehend). f) Aeusscre Zone der Cystenwand (aus dicht gehäuften Rundzellen bestehend). g) Gefässdurchschnitt mit perivaseulären Rundzelleninfiltrationen.

Figur 8. Ein kleiner Abschnitt der Inhaltsmasse der Wand einer Cyste bei mittelstarker Vergrösserung $(1: 25)$. Färbung mit AlaunhaematoxylinEosin. c) Inhaltsmasse der Cyste. o) Eier von Distomum, reihenweise stehend. e) Innere, aus spindelförmigen Zellen und Kernen bestehende Zone der Cystenwand. f) deussere, aus Rundzellen bestehende Zone der Cystenwand. a) Marksubstanz in der nahen Umgebung der Cysten. i) Kleine Ausbuchtungen der Cystenwand, hier im Schnitt von der ganzen Cyste isolirt getroffen.

Figur 9. Kleines Stüok der Inhaltsmasse und der Cystenwand bei starker Vergrösserung. Färbung mit Eosin-Alaunhaematoxylin. c) Inhaltsmasse der Cyste. o) Eier von Distomum. e) Spindelförmige Zellen und Kerne der inneren Zone der Cystenwand. e') Ein Theil dieser Kerne sprossenartig nach der Inhaltsmasse zwischen den Eiern strebend. f) Aeussere, aus Rundzellen bestehende Zone der Cystenwand.

Figur 10. Ein kleiner Bezirk der Marksubstanz in der näheren Umgebung der Cyste. Starke Vergr. Färbung nach van Gieson. a) Marksubstanz. g) Gefässwand. ga') Gewuchertes adventitielles Gewebe. t) Exsudatmasse im perivasculären Raume. t') Grosse, rundliche, homogene Gebilde 
in der Marlssubstanz ron derselben Constitution wie die compacte Exsudatmasse.

Figur 11. Ein kleiner Abschnitt der Inhaltsmasse und der Wand einer Cyste. Färbung nach Weigert für elastische Fasern. Mittelstarke Vergr. c) Inhaltsmasse der Cyste. o) Eier von Distomum. e) Innere Zone der Cystenwand. f) Aeussere Zone der Cystenwand. a) Marksubstanz in der nahen Umgebung der Cyste.

Figur 12. Abgeschnürte Ausbuchtung einer Cyste (vergl. Figur 8i) bei starker Vergr. Färbung mit Alaun-Haematoxylin-Eosin. o) Eier von Distomum. e) Innere Zone der Cystenwand. e') Peripherische Schicht der Inhaltsmasse, in welche Rundzellen sprossenartig hineinragen (vergl. Figur $9 \theta^{\prime}$ ). f) Aeussere Zone der Cystenwand.

Figur 13. Blutgefässe in der Nachbarschaft der in Figur 12 dargestellten Ausbuchtung einer Cyste. Dieselbe Färbung. s) Lumen des Gefässes mit Blut vollkommen gefüllt. g) Gefässwand. $\mathrm{g}^{\prime}$ ) Rundzellenschicht der Adventitia.

\section{Literatur.}

Taniguchi, Zwei Fälle der Lungendistomumcysten in der Augenhöhle und dem Hodensack. Tokyo-med. Zeitschr. 1892.

Miyake, Tokyo-med. Zeitschr. 1893.

Wakabayashi, Tokyo-med. Zeitschr. 1902.

0tani, Zeitschr. der med. Ges. in Tokyo. 1887-1888.

Inouje, Zeitschr. der med. Ges. in Tokyo.

Yamagiwa, Beiträge zur Aetiologie der Jackson's Epilepsie. Virchow's Archiv. CXIX.

Yamagiwa, Ueber die Lungen-Distomenkrankheiten in Japan. Virchow's Archiv. CXXVII.

Katzurada, Beiträge zur Kenntniss des Distomum Westermani. Pathol. und anat. Beiträge Bd. 28.

Baely, Ueber einige neue Parasiten des Menschen. Berliner klin. Wochenschrift. 1883.

Braun, Die thierischen Parasiten des Menschen. 3. Auflage. 1903.

Leuckart, Die Parasiten des Menschen. 2. Aufl. 1889.

Bernhardt, Beiträge zur Lehre von der Athetosis und vasomotor. Neurose der Extremitäten. Dieses Archiv Bd. 12.

v. Monakow, Gehimpathologie. Nothnagel's Specielle Pathologie und Therapie. 1897 . 


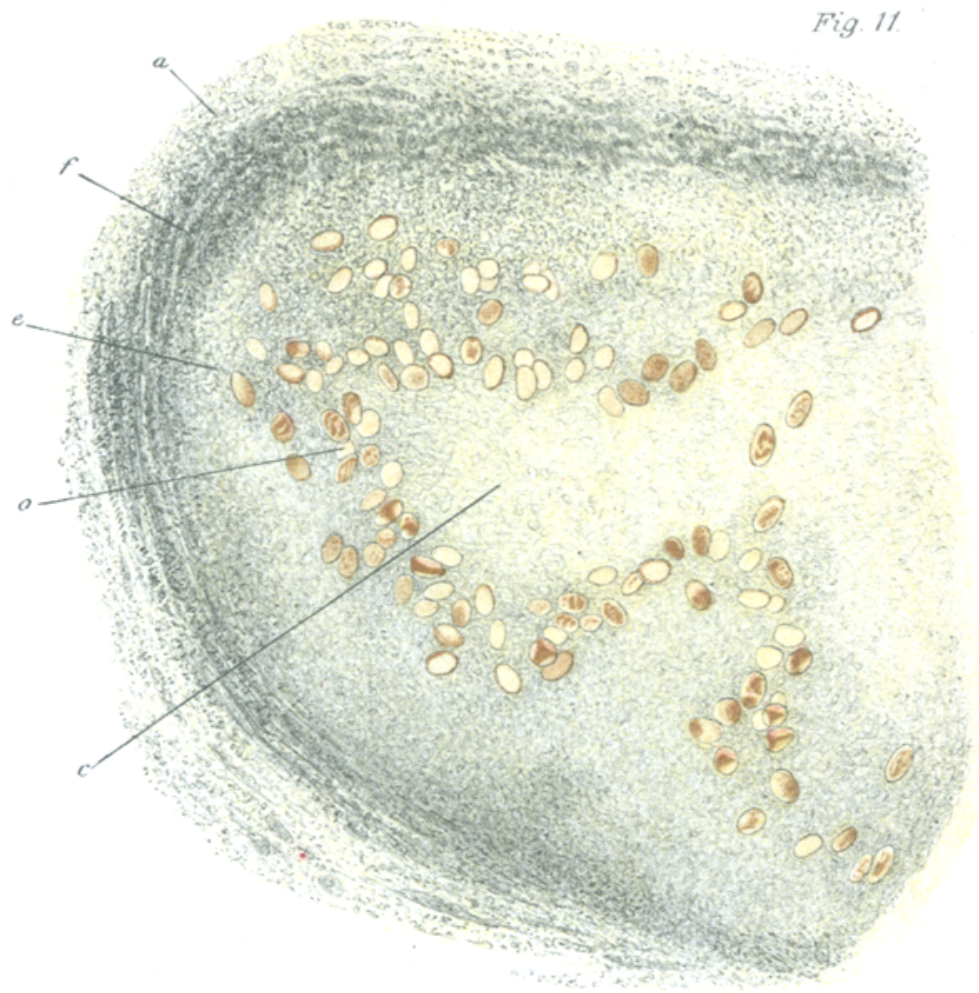

Fig. 12
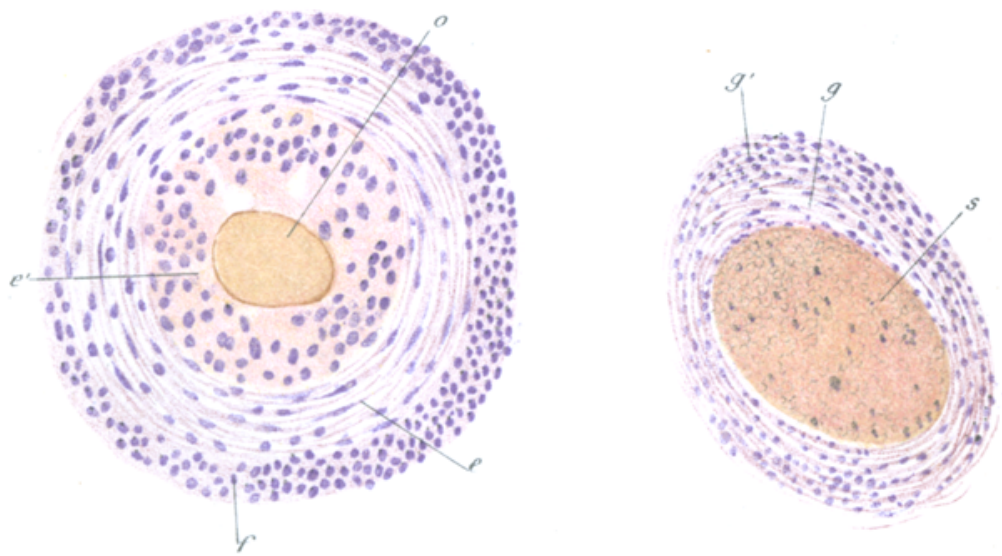

ELaue, Liti. Irsh, Bertin. 